\title{
Bovine lactoferrin inhibits lung cancer growth through suppression of both inflammation and expression of vascular endothelial growth factor
}

\author{
Yu-Tang Tung, ${ }^{* 1}$ Hsiao-Ling Chen, $\dagger^{1}$ Chih-Ching Yen, ${ }^{*} \ddagger^{1}$ Po-Ying Lee, $\S$ Hsin-Chung Tsai, ${ }^{*}$ Ming-Fong Lin, ${ }^{*}$ \\ and Chuan-Mu Chen*2 \\ ${ }^{*}$ Department of Life Sciences, Agricultural Biotechnology Center, National Chung Hsing University, Taichung 402, Taiwan \\ †Department of Bioresources and Molecular Biotechnology, Da-Yeh University, Changhwa 515, Taiwan \\ ‡Department of Internal Medicine, China Medical University, Taichung 404, Taiwan \\ §Department of Surgery, National Taiwan University Hospital Yun-Lin Branch, Yun-Lin 640, Taiwan \\ \#Taichung Hospital, Department of Health, Taichung 403, Taiwan
}

\section{ABSTRACT}

Lung cancers are among the most common cancers in the world, and the search for effective and safe drugs for the chemoprevention and therapy of pulmonary cancer has become important. In this study, bovine lactoferrin (bLF) was used in both in vitro and in vivo approaches to investigate its activity against lung cancer. A human lung cancer cell line, A549, which expresses a high level of vascular endothelial growth factor (VEGF) under hypoxia, was used as an in vitro system for bLF treatment. A strain of transgenic mice carrying the human VEGF- $\mathrm{A}_{165}\left(\mathrm{hVEGF}-\mathrm{A}_{165}\right)$ gene, which induces pulmonary tumors, was used as an in vivo lung cancer therapy model. We found that bLF significantly decreased proliferation of A549 cells by decreasing the expression of VEGF protein in a dosedependent manner. Furthermore, oral administration of $\mathrm{bLF}$ at $300 \mathrm{mg} / \mathrm{kg}$ of body weight 3 times a week for 1.5 mo to the transgenic mice overexpressing hVEGF$\mathrm{A}_{165}$ significantly eliminated expression of hVEGF- $\mathrm{A}_{165}$ and suppressed the formation of tumors. Additionally, treatment with bLF significantly decreased the levels of proinflammatory cytokines, such as tumor necrosis factor- $\alpha$, and antiinflammatory cytokines, such as IL-4 and IL-10. Levels of IL-6, which is both a proinflammatory and an antiinflammatory cytokine, were also reduced. Treatment with bLF decreased levels of tumor necrosis factor- $\alpha$, IL-4, IL-6, and IL-10 cytokines, resulting in limited inflammation, which then restricted growth of the lung cancer. Our results revealed that bLF is an inhibitor of angiogenesis and blocks lung cell inflammation; as such, it has considerable potential for therapeutic use in the treatment of lung cancer.

Received September 13, 2012.

Accepted December 24, 2012.

${ }^{1}$ These authors contributed equally to this work.

${ }^{2}$ Corresponding author: chchen1@dragon.nchu.edu.tw
Key words: bovine lactoferrin, pulmonary cancer, vascular endothelial growth factor (VEGF), transgenic mice

\section{INTRODUCTION}

For several decades, lung cancer has been the most common cancer worldwide (Li et al., 2010). Most new cases of lung cancer now occur in developing countries $(55 \%)$ and it is still the most common type of cancer in men (1.1 million cases, $16.5 \%$ of the total), with high rates in central, eastern, and southern Europe, North America, and East Asia (Ferlay et al., 2010). Although the treatment of lung cancer has improved, the mortality rate of lung cancer patients remains high. To reduce these high rates of mortality, many researchers have focused on methods for tumor prevention in addition to more effective treatments (Lin et al., 2009). Recently, researchers have found natural food components or products of digestion that could mediate the process of angiogenesis and metastasis (Singh et al., 2006; Yang and Wang, 2010). Researchers have shown the anticancer potential of dietary proteins, peptides, and amino acids, which may be natural products of fermentation and enzymatic hydrolysis or products of gastrointestinal digestion (de Mejia and Dia, 2010). These compounds mediate apoptosis and angiogenesis, which are vital steps in controlling tumor metastasis.

Bovine lactoferrin (bLF), a siderophilic protein with 2 iron-binding sites, has a wide range of biological activities, including anticancer effects, antimicrobial effects, and improvement of immunomodulatory functions (de Mejia and Dia, 2010). Chemopreventive and cell growth inhibitory activities of bLF have been demonstrated in esophageal (Ushida et al., 1999), lung (Li et al., 2011), colon (Tsuda et al., 1998), bladder (Masuda et al., 2000), mammary (Yamada et al., 2008; Duarte et al., 2011), stomach (Xu et al., 2010), and tongue (Tanaka et al., 2000) cancers. The anticancer functions of bLF are thought to be exerted through its innate 
ability to bind iron (González-Chávez et al., 2009). The iron could accelerate oxidation, thereby disrupting nucleic acid structure. Other potential mechanisms of anticancer functions include induction of programmed cell death and regulation of cell cycle protein expression (Lönnerdal and Iyer, 1995; Rodrigues et al., 2009). However, the antiangiogenesis effects of bLF during tumor growth are poorly understood.

In the early stages of cancer, the unregulated proliferation of cancer cells leads to a deficiency of both nutrients and oxygen, causing significant cell death. Cell death triggers an inflammatory response, activates hypoxia-inducible factor $1 \alpha$ (HIF-1 $\alpha)$, promotes the expression of the vascular endothelial growth factor (VEGF)-A mRNA, and causes angiogenesis. Of the VEGF family, VEGF-A is the one of most interest in human medicine for specialists and medical teams. Four isoforms of VEGF-A are known, including VEGF-A $\mathrm{A}_{121}$, VEGF-A ${ }_{165}$, VEGF-A 189 , and VEGF-A 206 ; VEGF-A 165 , the common type, primarily functions to promote angiogenesis. Secreted VEGF- $\mathrm{A}_{165}$ binds to the receptor VEGFR2 and activates a downstream signal that induces vasculogenesis (Ferrara, 2002). When cancer cells secrete a large amount of VEGF-A $\mathrm{A}_{165}$, vasculogenesis is induced to provide sufficient nutrients and oxygen to the tumor, thus increasing the tumor growth rate. Expression of VEGF- $\mathrm{A}_{165}$ is positively related to the growth and spread of cancer cells (Coussens and Werb, 2002). Therefore, the development of medicines that target VEGF- $\mathrm{A}_{165}$ is an important topic of study.

In this study, we used both in vitro and in vivo approaches to investigate the effects of VEGF expression in lung cancers treated with bLF, which was purified from bovine milk. Human lung cancer cells and an animal model of human (h)VEGF- $\mathrm{A}_{165}$-induced lung tumor transgenic mice were applied to examine the protection mechanisms of bLF on human and mouse lung carcinomas.

\section{MATERIALS AND METHODS}

\section{Cell Culture}

Human lung adenocarcinoma cell lines A549 [American Type Culture Collection (ATCC), Manassas, VA; cat. no. CCL-185] and CL1-0 (provided by J. J. W. Chen, Institute of Biomedical Science, National Chung Hsing University, Taichung, Taiwan; Chen et al., 2001) and the human bronchial epithelial cell line Beas 2B (ATCC; cat. no. CRL-9609) were cultured in Dulbecco's modified Eagle's medium (DMEM) supplemented with $10 \%$ fetal bovine serum (FBS). Cells were incubated in a $5 \% \mathrm{CO}_{2}$ incubator at $37^{\circ} \mathrm{C}$ (Chen et al., 2008c).

\section{Cell Viability Assay}

To measure the cytotoxicity of bLF (Sigma-Aldrich, St. Louis, MO) on cell proliferation, A549, CL1-0, and Beas $2 \mathrm{~B}$ cells $\left(2 \times 10^{5}\right.$ cells/well $)$ were seeded into a 96-well plate in triplicate and incubated for $3 \mathrm{~h}$ to allow cell adherence. First, $200 \mu \mathrm{L}$ of fresh medium containing various concentrations of bLF (15 to 0.9375 $\mathrm{mg} / \mathrm{mL}$ ) or $\mathrm{H}_{2} \mathrm{O}$ (control) was added into the cultures and incubated at $37^{\circ} \mathrm{C}$ for $48 \mathrm{~h}$. Following the removal of the medium from the wells, $100 \mu \mathrm{L}$ of tetrazolium salt solution $[1 \mathrm{~mL}$ of 3-(4,5-dimethylthiazol-2-yl)-2,5diphenyltetrazolium bromide (MTT) in $10 \mathrm{~mL}$ of DMEM] was added. After $4 \mathrm{~h}$ of incubation at $37^{\circ} \mathrm{C}$, the medium was removed and $100 \mu \mathrm{L}$ of dimethyl sulfoxide (DMSO) was added to dissolve the formazan crystals. Absorbance was measured in an ELISA reader at 570 $\mathrm{nm}$ (Yen et al., 2009). The cell viability ratio (\%) was calculated as follows: $\%$ viability $=($ absorbance of test sample/absorbance of control) $\times 100 \%$.

\section{Growth Curve and Doubling Time}

The A549 cell line was used to generate a growth curve using a 24-well microtiter plate. A seeding density of 1,500 cells in a 1-mL volume of DMEM supplemented with $10 \%$ FBS was used per well. Growing cultures were trypsinized at d 1, 4, 7, 8, 9, and 10, and the number of live cells per well was determined in triplicate (Chen et al., 2010). The doubling time (in hours) was calculated as $\mathrm{h} \times \ln (2) / \ln (\mathrm{c} 2 / \mathrm{c} 1)$, where $\mathrm{c} 1$ and $\mathrm{c} 2$ are the cell concentrations at the beginning and the end of the chosen period of time.

\section{Reverse-Transcription PCR Analysis}

The A549 cells were seeded in a 10 -cm dish at 5 $\times 10^{6}$ cells/well. After $2 \mathrm{~d}, 10 \mathrm{~mL}$ of DMEM supplemented with $10 \%$ FBS or $0.1 \%$ FBS and containing various concentrations of bLF $(100,50,25,12.5$, and $6.25 \mathrm{mg}$ per $10-\mathrm{cm}$ dish) was added to the cultures and incubated at $37^{\circ} \mathrm{C}$ for $48 \mathrm{~h}$. The reverse-transcription PCR (RT-PCR) protocol was described previously (Hung et al., 2010; Tsai et al., 2010). Primers for vegf were 5'-CAGAAGCAG AATGTGACCATC-3' (sense) and 5'-CTTCTGGTCGATGTCATGAGC-3' (antisense). $\beta$-Actin was used as an internal control with the following primers: 5'-CCGTCTTCCCCTCCATCGTGGG-3' (sense) and 5'-CGCAGCTCATTGTAGAAG GTGTGG-3' (antisense). The amplified RT-PCR products were analyzed with $2 \%$ agarose gel electrophoresis containing ethidium bromide (Tung et al., 2011). 


\section{Western Blotting}

Cells were homogenized in $300 \mu \mathrm{L}$ of RIPA (radioimmunoprecipitation assay) buffer $[5 \mathrm{~m} M$ Tris-HCl, $\mathrm{pH}$ 7.4, $0.15 \mathrm{M} \mathrm{NaCl}, 1 \%$ Nonidet P40, $0.25 \%$ sodium deoxycholate, $5 \mathrm{~m} M$ EDTA, and $1 \mathrm{~m} M$ ethylene glycolbis(2-aminoethyl-ether)- $N, N, N^{\prime}, N^{\prime}$-tetraacetic acid, EGTA; Chen et al., 2008c] and the homogenates were centrifuged at $12,000 \times g$ for $30 \mathrm{~min}$ at $4^{\circ} \mathrm{C}$. Protein $(40 \mu \mathrm{g})$ was then separated by $10 \%$ SDS-PAGE and electrotransferred to polyvinyl difluoride membranes. The membranes were incubated in blocking solution for $2 \mathrm{~h}$ and then incubated with primary antibody (anti-VEGF-A or anti-GAPDH) overnight at $4^{\circ} \mathrm{C}$. After washing, the membranes were incubated with a goat anti-rabbit IgG peroxidase-conjugated secondary antibody directed against the primary antibody. The membranes were developed using an enhanced chemiluminescence Western blot detection system (Chen et al., 2008a).

\section{Homozygous Transgenic Mouse Production}

The mccsp-hVegf- $\mathrm{A}_{165}$-sv40poly(A) transgenic mice were generated by pronuclear microinjection (Tung et al., 2011). To detect the hVEGF- $\mathrm{A}_{165}$ transgene in the transgenic mice with a homozygous (hVEGF$\mathbf{A}_{165}{ }^{+/}$) or heterozygous (hVEGF- $\mathbf{A}_{165}{ }^{+/-}$) genotype, the mice were analyzed by RT-PCR of lung tissue mRNA with the primer set of VEGF-94(+): 5'-AAGGAGGAGGGCAGAATCATC- $3^{\prime}$ and VEGF315(-): 5'-GAGGTTTGATCCGCATAATCTG-3' . The exogenic human VEGF-A $A_{165}$ protein expression levels in homozygous (hVEGF- $\mathrm{A}_{165}{ }^{+/+}$) or heterozygous $\left(\mathrm{hVEGF}-\mathrm{A}_{165}{ }^{+-}\right.$) transgenic mice were also detected by Western blot as described above.

\section{Animal Trials}

The transgenic mice were given a standard laboratory diet and distilled water ad libitum and kept on a 12 -h light/dark cycle at $22 \pm 2^{\circ} \mathrm{C}$. This animal study was approved by the Institutional Animal Care and Utilization Committee of National Chung Hsing University. The transgenic mice with the homozygous (hVEGF$\mathrm{A}_{165}{ }^{+/+}$) genotype were randomly assigned into 2 groups for treatment $(\mathrm{n}=6)$ : (1) transgenic mice treated with PBS as mock control (Tg/Mock) and (2) transgenic mice treated with bLF $(\mathbf{T g} / \mathbf{b L F})$ groups. After oral administration of bLF at $300 \mathrm{mg} / \mathrm{kg}$ of BW 3 times a week, mice were killed at 10.5 mo of age, following 1.5 mo of bLF administration. Lung tissues were collected for pathological histology, immunohistochemistry stain- ing, and RNA and protein extractions. All experiments were repeated twice.

\section{Histopathology Examination}

Lung tissue was fixed in $10 \%$ buffered formaldehyde ( $\mathrm{pH}$ 7.0), embedded with paraffin, sectioned into $3-\mu \mathrm{m}$ sections, and examined using hematoxylin and eosin (H\&E) staining (Chen et al., 2008b). Scores of lung histopathology were examined by 2 independent pathologists.

\section{Immunohistochemistry Staining}

Formaldehyde-fixed and paraffin-embedded sections were prepared accordingly (Hung et al., 2010). The sections were incubated in $3 \%$ hydrogen peroxide for 10 min to block endogenous peroxidase activity and then incubated overnight at $4^{\circ} \mathrm{C}$ with primary rabbit monoclonal antibody against hVEGF-A using a 1:40 working dilution. For antigen retrieval, the sections were immunostained with the Vectastain $\mathrm{ABC}$ kit (Universal, Vector Laboratories Inc., Burlingame, CA) as described previously (Tung et al., 2011). Diaminobenzidine (DAB) was used for staining development, and the sections were counterstained with hematoxylin (Liu et al., 2008). The negative control consisted of substituting normal serum for the primary antibody.

\section{Real-Time RT-PCR}

Real-time RT-PCR was performed using Rotor-Gene SYBR Green kit (Corbett Research, Mortlake, New South Wales, Australia). To evaluate gene expression, real-time RT-PCR was performed on 3 genes: vegf, IL6 , and tumor necrosis factor- $\alpha(T N F-\alpha)$ using cDNA from lung tissues; $\beta$-actin was used as an internal control (Chen et al., 2003).

\section{ELISA for Cytokines}

Blood samples were collected and centrifuged at 1,400 $\times g$ at $4^{\circ} \mathrm{C}$ for $15 \mathrm{~min}$, and concentrations of VEGF, TNF- $\alpha$, IL-4, IL-6, and IL-10 in serum supernatants were determined using the commercial kits from PeproTech Inc. (Rocky Hill, NJ; Chen et al., 2010).

\section{Statistical Analysis}

Data were presented as means \pm standard error (SE) or means \pm standard deviations (SD). The data in Figure 1 and Figure 2 were calculated by Scheffé's test and values $<0.05$ were considered to be significant 


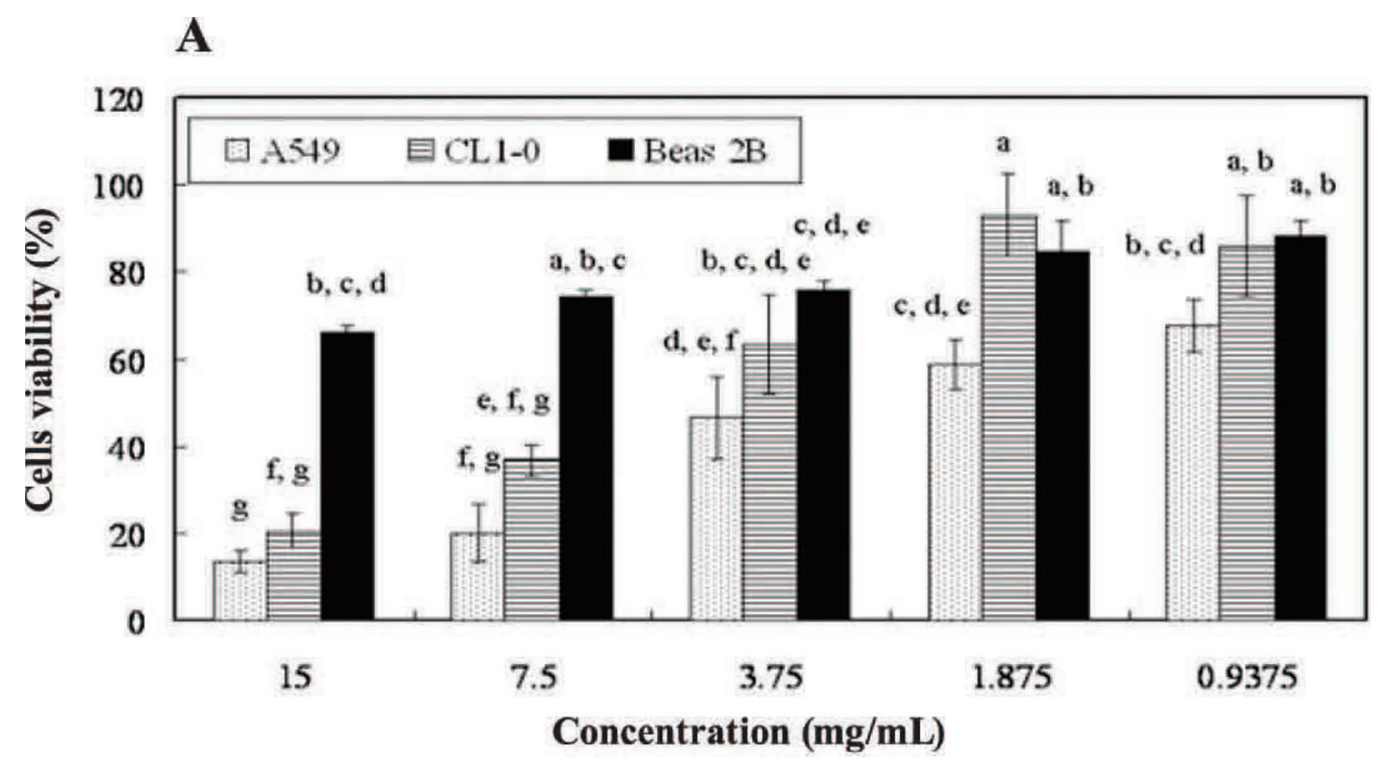

B

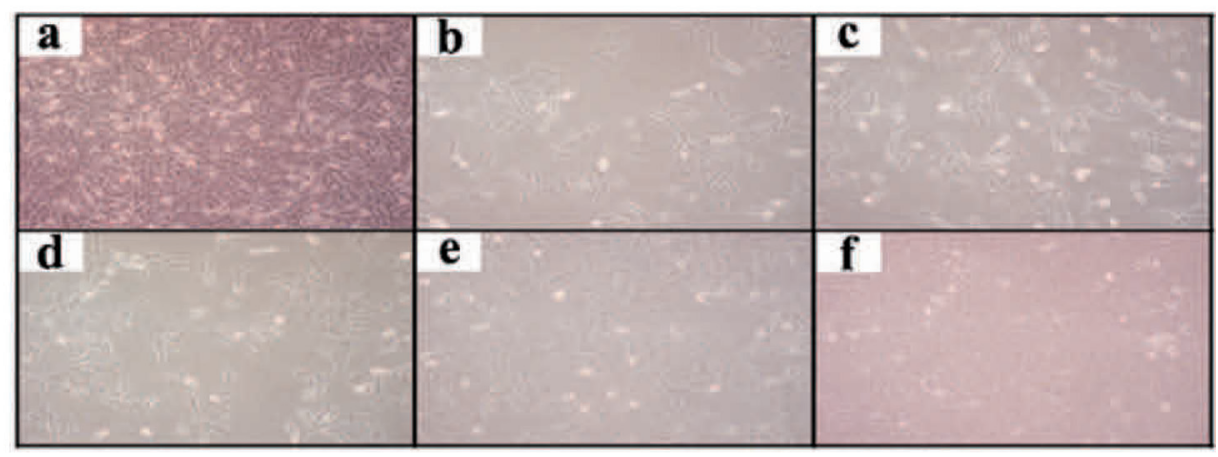

C

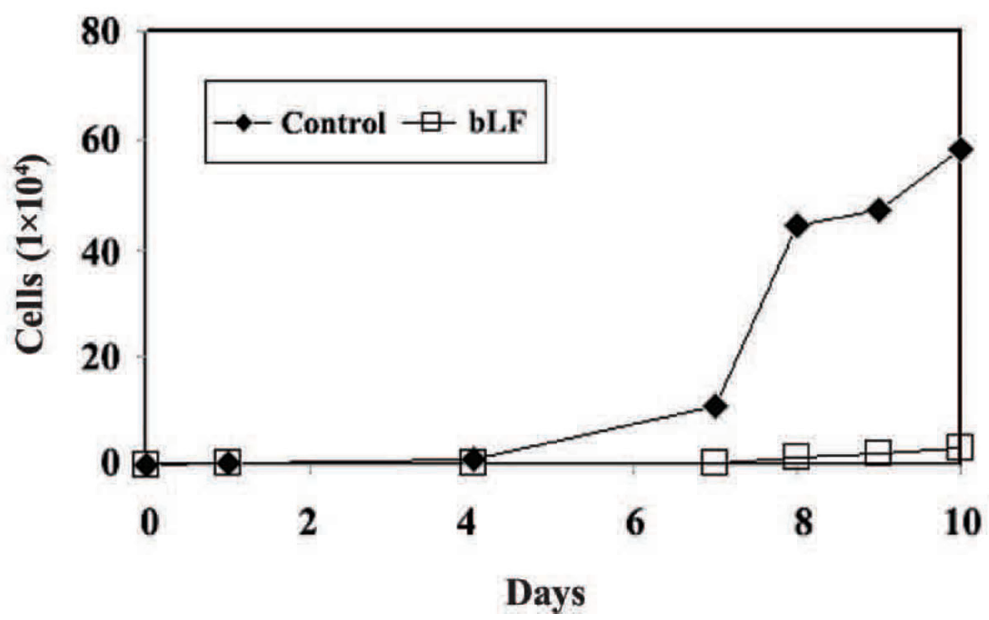

Figure 1. Analyses of bovine lactoferrin (bLF) on lung cancer cell viability, morphological changes, and growth. (A) Effects of bLF over a range of concentrations $(15,7.5,3.75,1.875$, and $0.9375 \mathrm{mg} / \mathrm{mL}$ ) on the cell viability of A549, CL1-0 (both lung cancer cell lines), and Beas 2B cells (normal lung cells) after $24 \mathrm{~h}$ of incubation. The significance of difference was calculated by Scheffé's test, and results with $P<0.05$ were labeled with different letters and considered statistically significant. (B) A549 cells were treated without (a) or with (b: 15, c: 7.5, d: 3.75, e: 1.875 , and f: $0.9375 \mathrm{mg} / \mathrm{mL}$ ) bLF for $48 \mathrm{~h}$. The cells were examined and photographed (100× magnification) under phase-contrast microscopy. (C) A549 cells treated without or with bLF $(3 \mathrm{mg} / \mathrm{mL})$ in 24-well microtiter plates for various time points $(1,4,7,8,9$, and $10 \mathrm{~d})$ were cultured, and the total number of cells was plotted against time. Color version available in the online PDF. 

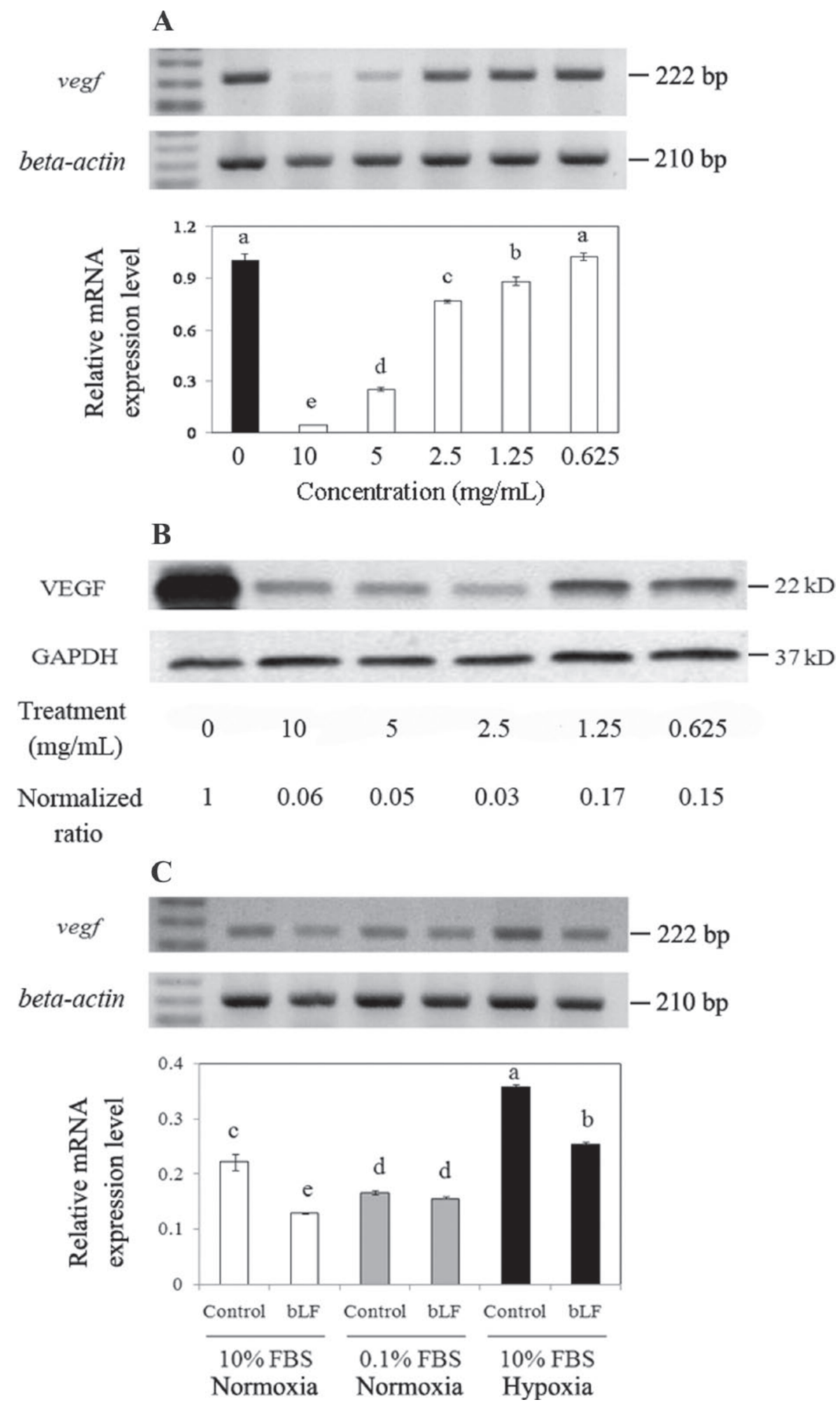

Figure 2. Expressions of vascular endothelial growth factor mRNA (vegf) and protein (VEGF) in A549 cells treated with bovine lactoferrin (bLF) after $48 \mathrm{~h}$ of incubation. (A) The expression of vegf mRNA treated without or with various doses $(10,5,2.5,1.25$, and $0.625 \mathrm{mg} / \mathrm{mL})$ of bLF. The significance of difference was calculated by Scheffé's test; results with $P<0.05$ were labeled with different letters and considered statistically significant. (B) The expression of VEGF protein treated without or with various doses $(10,5,2.5,1.25$, and $0.625 \mathrm{mg} / \mathrm{mL})$ of bLF as measured using Western blotting. (C) A549 cells treated with bLF (3 mg/mL) were cultured in Dulbecco's modified Eagle medium (DMEM) supplemented with $10 \%$ or $0.1 \%$ fetal bovine serum (FBS) under normal or hypoxic conditions $\left(95 \% \mathrm{~N}_{2}\right.$ and $\left.5 \% \mathrm{CO}_{2}\right)$. The significance of difference was calculated by Scheffé's test; results with $P<0.05$ were labeled with different letters and considered statistically significant. 
A
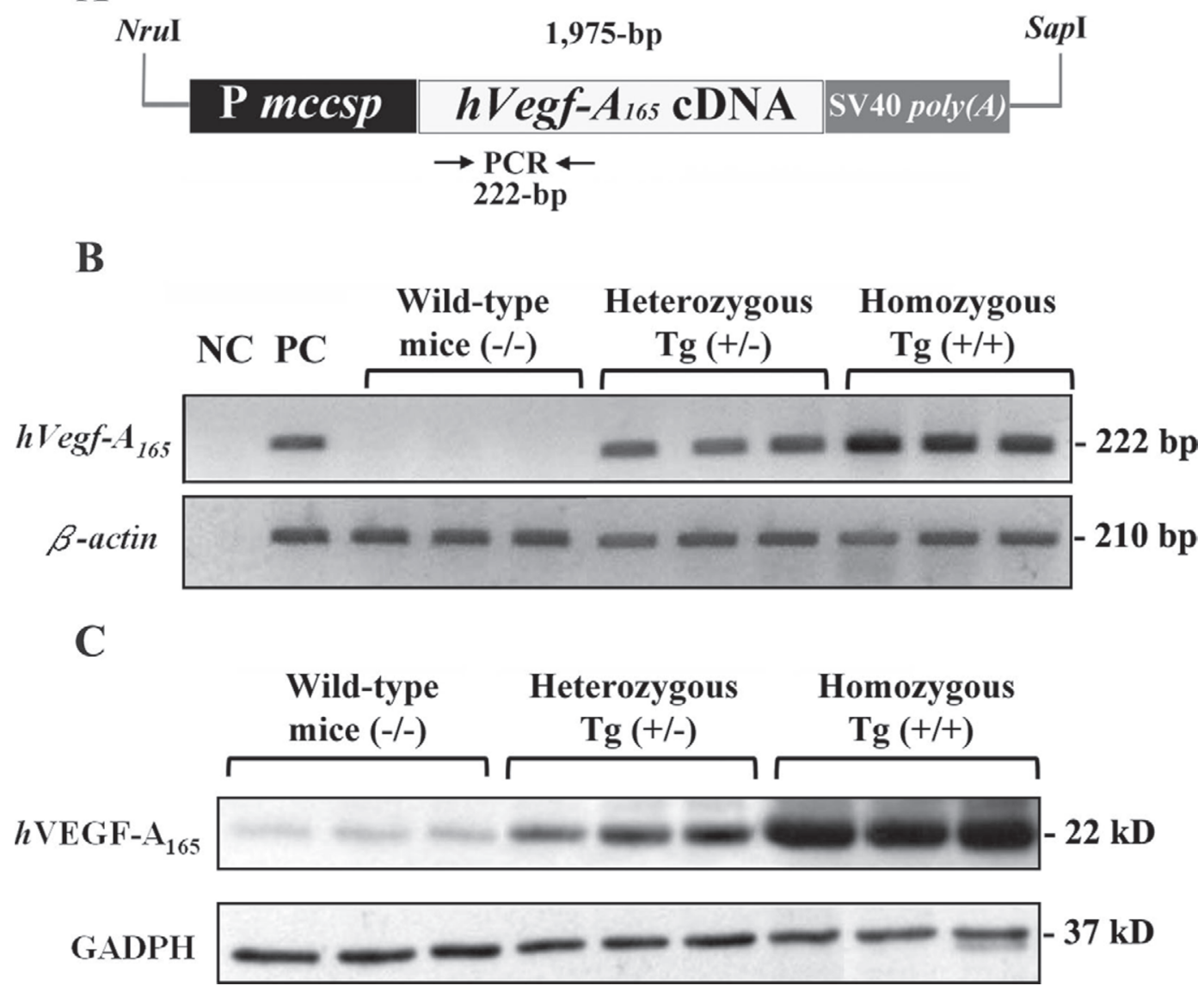

Figure 3. Generation of lung-specific human vascular endothelial growth factor (VEGF) isoform $\mathrm{A}_{165}\left(\mathrm{hVEGF}-\mathrm{A}_{165}\right)$-overexpressing transgenic (Tg) mice. (A) The structure map of mccsp-hVegf- $\mathrm{A}_{165}$-sv40poly(A) transgene. The 1,975-bp NruI-SapI segment of the $h$ Vegf- $A_{165}$ cDNA carries the promoter region of $m c c s p$ and the polyadenosine [poly $(\mathrm{A})]$ signal sequence of the sv40gene. (B) reverse-transcription PCR analysis of vegf mRNA expression in heterozygous $\left(\mathrm{hVEGF}-\mathrm{A}_{165}{ }^{+-}\right.$) or homozygous $\left(\mathrm{hVEGF}-\mathrm{A}_{165}{ }^{++}\right.$) transgenic mice. $\mathrm{NC}=$ negative control; $\mathrm{PC}=$

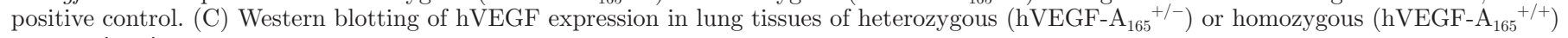
transgenic mice.

(Chen et al., 2008d). Data in Figure 5 and Figure 6 were analyzed by $t$-test, and statistical significances are presented as $P<0.05\left(^{*}\right)$ and $P<0.01\left(^{* *}\right)$.

\section{RESULTS}

\section{Effects of bLF on Lung Cancer Cell Viability, Morphological Changes, and Growth}

Two human lung adenocarcinoma cell lines, A549 and CL1-0, were treated with bLF (at 15, 7.5, 3.75, 1.875 , and $0.9375 \mathrm{mg} / \mathrm{mL}$ ) for $48 \mathrm{~h}$. This treatment decreased cell viability in a concentration-dependent manner compared with untreated controls (Figure 1A). Additionally, the MTT assay revealed that concentrations up to $15 \mathrm{mg} / \mathrm{mL}$ of bLF treatment produced no significant cytotoxic effects on normal lung cells (Beas $2 \mathrm{~B})$. The median lethal dose $\left(\mathrm{LD}_{50}\right)$ values of
bLF treatment were 3.2 and $5.6 \mathrm{mg} / \mathrm{mL}$ for $\mathrm{A} 549$ and CL1-0 cells, respectively (Figure 1A); bLF was able to successfully inhibit the growth of A549 and CL1-0 cells. Chang et al. (2004) showed that A549 cells have greater invasive and metastatic abilities than CL1-0 cells. Thus, in this study, we focused on elucidating the anticancer effect of bLF in A549 cells.

After the A549 cells were treated with bLF $(10,5$, $2.5,1.25$, and $0.625 \mathrm{mg} / \mathrm{mL}$ ) for $48 \mathrm{~h}$, they underwent significant morphologic changes, as shown in Figure 1B. This result ruled out a possible cytotoxic effect of bLF in A549 lung cancer cells, supporting a negative effect of bLF on cell proliferation. To determine the effect of bLF on the growth of A549 cells, the cells were treated with $(3 \mathrm{mg} / \mathrm{mL})$ or without bLF in 24-well microtiter plates for various times $(1,4,7,8,9$, and $10 \mathrm{~d})$, and the total number of cells was plotted (Figure 1C). From the log phase of the curve, the population doubling time of 


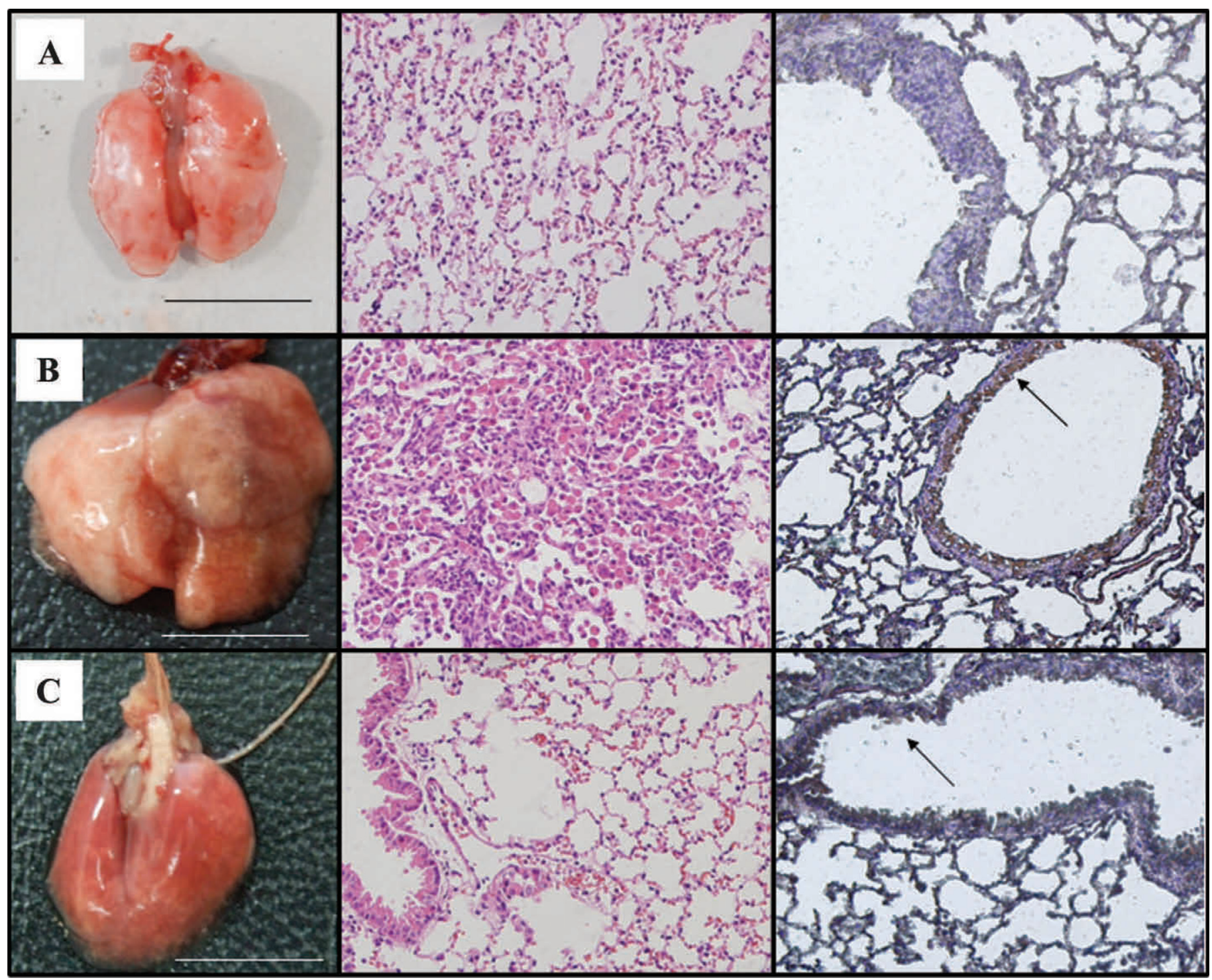

Figure 4. The exterior, histopathological, and immunohistochemical (IHC) analyses of the lung tissues of 10.5-mo-old human vascular endothelial growth factor (VEGF) isoform $\mathrm{A}_{165}\left(\mathrm{hVEGF}-\mathrm{A}_{165}\right.$ )-overexpressing transgenic mice. (A) Wild-type mice treated with PBS alone (WT group); (B) transgenic mice treated with PBS alone (Tg/Mock group); (C) transgenic mice treated with bLF at $300 \mathrm{mg} / \mathrm{kg}$ of BW 3 times a week for $1.5 \mathrm{mo}(\mathrm{Tg} / \mathrm{bLF}$ group). Arrows indicate the IHC staining signals. Scale bar $=1 \mathrm{~cm}$.

A549 cells treated with or without bLF was 59.3 and $23.5 \mathrm{~h}$, respectively, indicating that A549 cells treated with bLF grew more slowly than untreated A549 cells.

\section{bLF Suppresses VEGF Expression in A549 Lung Cancer Cells}

The effect of bLF on vegf mRNA expression was investigated as shown in Figure 2A. Results showed that bLF inhibited expression of vegf in a dose-dependent manner; approximately 12 and $75 \%$ reductions were observed at 1.25 and $5 \mathrm{mg} / \mathrm{mL}$ bLF, respectively. At concentrations up to $10 \mathrm{mg} / \mathrm{mL}$, bLF almost completely inhibited the expression of vegf mRNA in A549 cells. Additionally, in A549 cells treated with bLF (10, 5, $2.5,1.25$, and $0.625 \mathrm{mg} / \mathrm{mL}$ ) for $48 \mathrm{~h}$, the expression of VEGF protein decreased in a concentration-dependent manner compared with untreated control (Figure 2B). Results for VEGF protein expression were the same as those for vegf mRNA expression.

Early stage cancer cells will continue to proliferate in vivo, leading to deficiencies in both nutrients and oxygen. To imitate the growth environment of the cancer cells in vivo, cells were cultured in DMEM supplemented with $10 \%$ FBS or $0.1 \%$ FBS in normoxia or hypoxia $\left(95 \% \mathrm{~N}_{2}\right.$ and $\left.5 \% \mathrm{CO}_{2}\right)$ conditions. In the present study, 
Table 1. Lung tumorigenesis frequency (number; \% in parentheses) in mouse lung tissues of different groups using histopathological image analysis

\begin{tabular}{lccc}
\hline & \multicolumn{3}{c}{ Group $^{1}$} \\
\cline { 2 - 3 } Pathological characteristic & Wild type & Tg/Mock & Tg/bLF \\
\hline Normal & $5(83.3)$ & $0(0)$ & $2(33.3)$ \\
Cyst & $1(16.7)$ & $3(50.0)$ & $3(50.0)$ \\
Damaged alveoli & $0(0)$ & $6(100)$ & $3(50.0)$ \\
Mild emphysematous change & $0(0)$ & $1(16.7)$ & $2(33.3)$ \\
Prominent emphysematous change & $0(0)$ & $5(83.3)$ & $1(16.7)$ \\
Hemosiderin-laden macrophages in alveoli & $0(0)$ & $3(50.0)$ & $3(50.0)$ \\
Old hemorrhage & $0(0)$ & $5(83.3)$ & $1(16.7)$ \\
Moderate lymphocytic infiltration & $0(0)$ & $3(50.0)$ & $2(33.3)$ \\
Marked chronic lymphoid infiltration & $0(0)$ & $3(66.7)$ & $1(16.7)$ \\
Neoplasm & $0(0)$ & $3(50.0)$ & $1(16.7)$ \\
Lymphoma & $0(0)$ & $1(16.7)$ & $1(16.7)$ \\
Adenocarcinoma & $0(0)$ & $4(66.7)$ & $1(16.7)$ \\
\hline
\end{tabular}

\footnotetext{
${ }^{1}$ Transgenic mice homozygous for the human vascular endothelial growth factor $\mathrm{A}_{165}$ isoform $\left(\mathrm{hVEGF}-\mathrm{A} 165^{+/+}\right.$) were randomly assigned into 2 groups for treatment $(\mathrm{n}=6)$ : (1) transgenic mice treated with PBS as mock control (Tg/Mock) and (2) transgenic mice treated with bovine lactoferrin (bLF; Tg/bLF). After oral administration of bLF at $300 \mathrm{mg} / \mathrm{kg}$ of BW 3 times a week for $1.5 \mathrm{mo}$, mice were killed at 10.5 mo of age and lung tissues were collected for histopathology.
}

vegf mRNA expression in A549 cells increased from a ratio of 0.22 to 0.36 after hypoxia treatment $(P<0.05)$. Among 3 conditions - $0.1 \%$ FBS in normoxia, $10 \%$ FBS in normoxia, or $10 \% \mathrm{FBS}$ in hypoxia - cells grown in $10 \%$ FBS and under hypoxia had the highest expression of the vegf gene (Figure 2C). In contrast, bLF administration markedly suppressed vegf mRNA expression in DMEM supplemented with 10\% FBS under both normoxia and hypoxia conditions $(P<0.05)$. Thus, bLF did reduce proliferation of lung cancer cells.

\section{Effects of bLF on Histopathology and Tumor Suppression in VEGF-Overexpressing Transgenic Mice}

We developed $\mathrm{hVEGF}-\mathrm{A}_{165^{-}}$-overexpressing transgenic mice carrying the mccsp-hVegf- $\mathrm{A}_{165}-\mathrm{Sv} 40$ poly(A) transgene (Figure 3A) to specifically express human VEGF$\mathrm{A}_{165}$ mRNA (Figure 3B) and protein (Figure 3C) in lung Clara cells (bronchiolar exocrine cells), which would induce lung tumor formation in homozygous transgenic mice around 10.5 mo of age. Lung exteriors of wild-type mice and $\mathrm{hVEGF}-\mathrm{A}_{165}$-overexpressing transgenic mice $>10.5$ mo are shown in the left-most panels of Figure 4. The lung tumors in the transgenic mice primarily included neoplasms growing on the periphery of the lung alveolus and adenomas growing on the site near the lung bronchus. In a lung alveolus on a lung bronchus of a transgenic mouse, some obvious, large-grained, pink cells were found (Figure 4B, middle panel). These pink cells are macrophages and are indicative of an inflammatory response. Results suggested that $\mathrm{hVEGF}-\mathrm{A}_{165}$ is capable of promoting vascular permeability and an effective inflammatory response. Furthermore, after oral administration of bLF at $300 \mathrm{mg} / \mathrm{kg}$ of $\mathrm{BW} 3$ times a week for $1.5 \mathrm{mo}$, the 10.5-mo-old transgenic mice (overexpressing hVEGF- $\mathrm{A}_{165}$ ) showed a dramatic decrease in solid tumor formation $(16.7 \%$; Table 1 and Figure 4C) compared with untreated transgenic mice (66.7\%; Table 1 and Figure 4B).

Immunohistochemical analysis showed that VEGF was overexpressed in the Clara cells of lung tissues from transgenic mice (Figure 4B, right panel) compared with wild-type mice (Figure $4 \mathrm{~A}$, right panel). In hVEGF- $\mathrm{A}_{165}$-overexpressing transgenic mice, treatment with bLF (Figure 4C, right panel) significantly reduced VEGF overexpression in Clara cells compared with untreated transgenic mice.

\section{bLF Decreases vegf, IL-6, and TNF- $\alpha$ mRNA Transcripts in VEGF-Overexpressing Transgenic Mice}

In the lung cancer cell study, we found that the vegf mRNA expression was significantly decreased in A549 cells after treatment with bLF. We expected that bLF could inhibit vegf mRNA expression, which is responsible for cell proliferation. The mRNA expression levels of vegf, $I L-6$, and $T N F-\alpha$ were markedly decreased $(P<$ $0.05)$ in the lungs of the Tg/bLF group compared with those of the Tg/Mock group; Figure 5A). Furthermore, Western blotting showed that the expression of VEGF was significantly decreased in the $\mathrm{Tg} / \mathrm{bLF}$ group compared with the Tg/Mock group (Figure 5B), suggesting that angiogenesis may be blocked because of the inhibition of VEGF expression by treatment with bLF. 


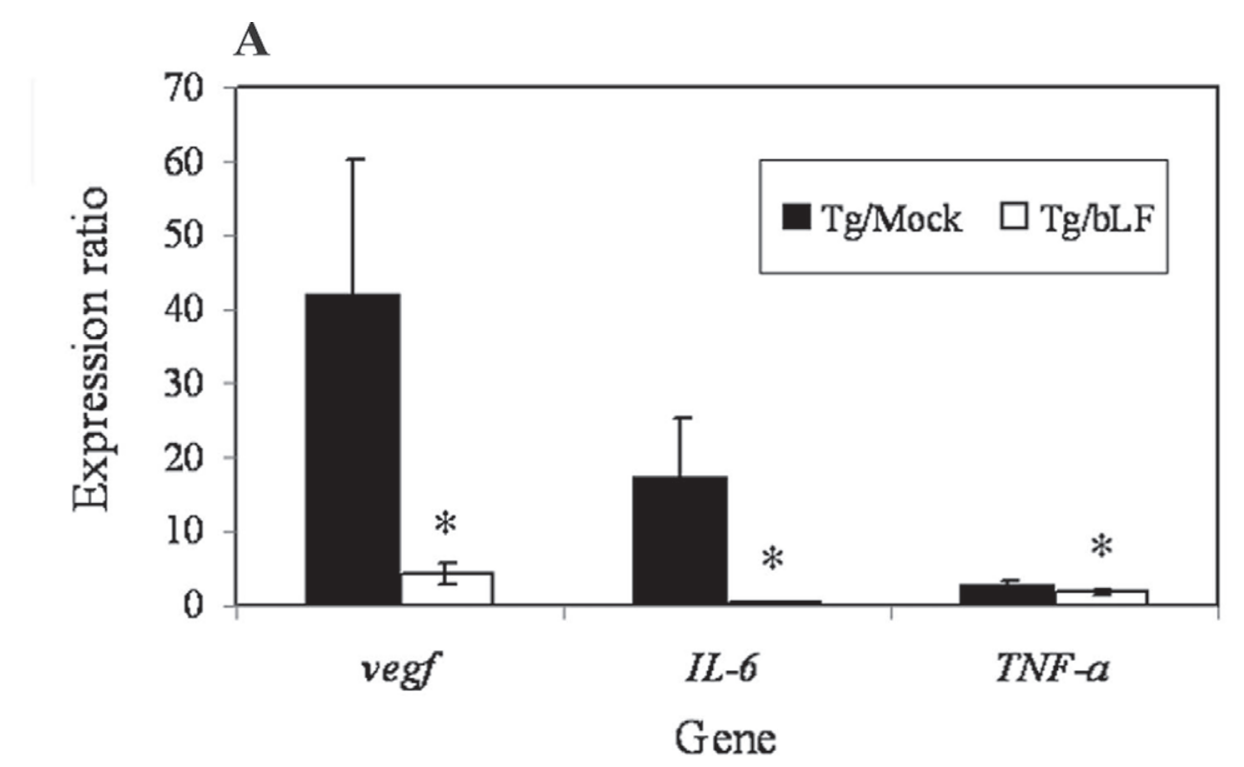

B

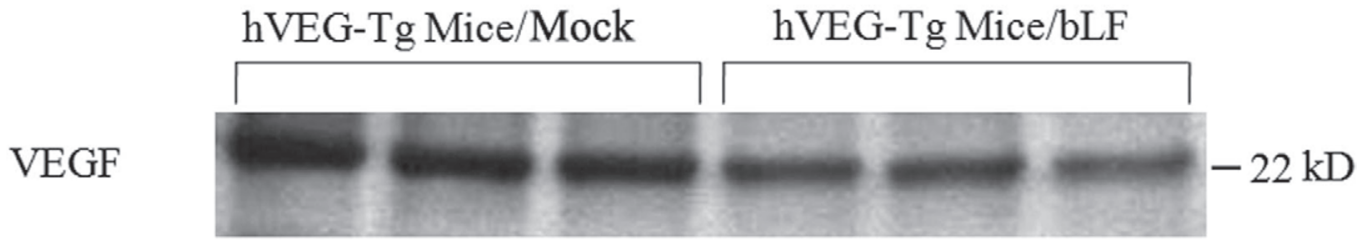

GAPDH

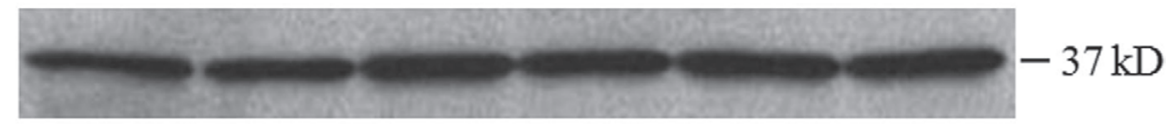

Ratio $\quad \begin{array}{llllll}1.0 & 0.60 & 0.53 & 0.37 & 0.37 & 0.25\end{array}$

Figure 5. Quantitative analyses of mRNA and protein expressions in the lung tissues of human vascular endothelial growth factor (VEGF) isoform $\mathrm{A}_{165}\left(\mathrm{hVEGF}-\mathrm{A}_{165}\right)$-overexpressing transgenic mice. (A) Real time-PCR validation of mRNA expression levels of vegf, IL-6, and tumor necrosis factor- $\alpha(T N F-\alpha)$ in the lung tissues of the transgenic mice treated with PBS alone $(\mathrm{Tg} / \mathrm{Mock}$ group) or with bLF at $300 \mathrm{mg} / \mathrm{kg}$ of BW 3 times a week for $1.5 \mathrm{mo}$ ( Tg/bLF group). The cDNA of $\beta$-actin was used as an internal control. Mean $\pm \mathrm{SEM}(\mathrm{n}=6) ;{ }^{*} P<0.05$ vs. Tg/ Mock group. (B) Expression of VEGF protein in the lung tissues of the Tg/Mock and $\mathrm{Tg} / \mathrm{bLF}$ groups measured using Western blotting. Mouse GADPH was used an internal control.

\section{bLF Suppresses Cytokine Levels in VEGF-Overexpressing Transgenic Mice}

The levels of VEGF-A, TNF- $\alpha$, IL-4, IL-6, and IL10 in the serum of $\mathrm{Tg} / \mathrm{bLF}$ and $\mathrm{Tg} /$ Mock groups are shown in Figure 6. The VEGF-overexpressing transgenic mice that underwent oral administration of bLF showed a significant reduction in serum VEGF (30 pg/ $\mathrm{mL})$, TNF- $\alpha$ (466 pg/mL), IL-4 (410 pg/mL), IL-6 $(377 \mathrm{pg} / \mathrm{mL})$, and IL-10 (696 pg/mL) concentrations compared with the Tg/Mock group $(P<0.01)$. These results demonstrate that oral administration of bLF at $300 \mathrm{mg} / \mathrm{kg}$ of BW could decrease concentrations of VEGF-A, TNF- $\alpha$, IL-4, IL-6, and IL-10, which may lead to restrictions in the growth of lung cancer cells.

\section{DISCUSSION}

In the initial stages of lung cancer, cancer cells keep proliferating and thus experience deficiencies in both nutrient and oxygen, leading to massive cell death. When cancer cells secret a large amount of VEGF- $\mathrm{A}_{165}$, vasculogenesis is induced to provide sufficient nutrients and oxygen to the tumor, therefore increasing the speed of tumor growth (Ferrara and Davis-Smyth, 1997). In this study, we demonstrated that bLF slowed the proliferation of A549 human lung cancer cells by decreasing expression of vegf mRNA and VEGF protein in a dosedependent manner (Figure 1). Because bLF exhibited no cytotoxicity on normal human bronchial epithelial cells under the same conditions, bLF warrants further 


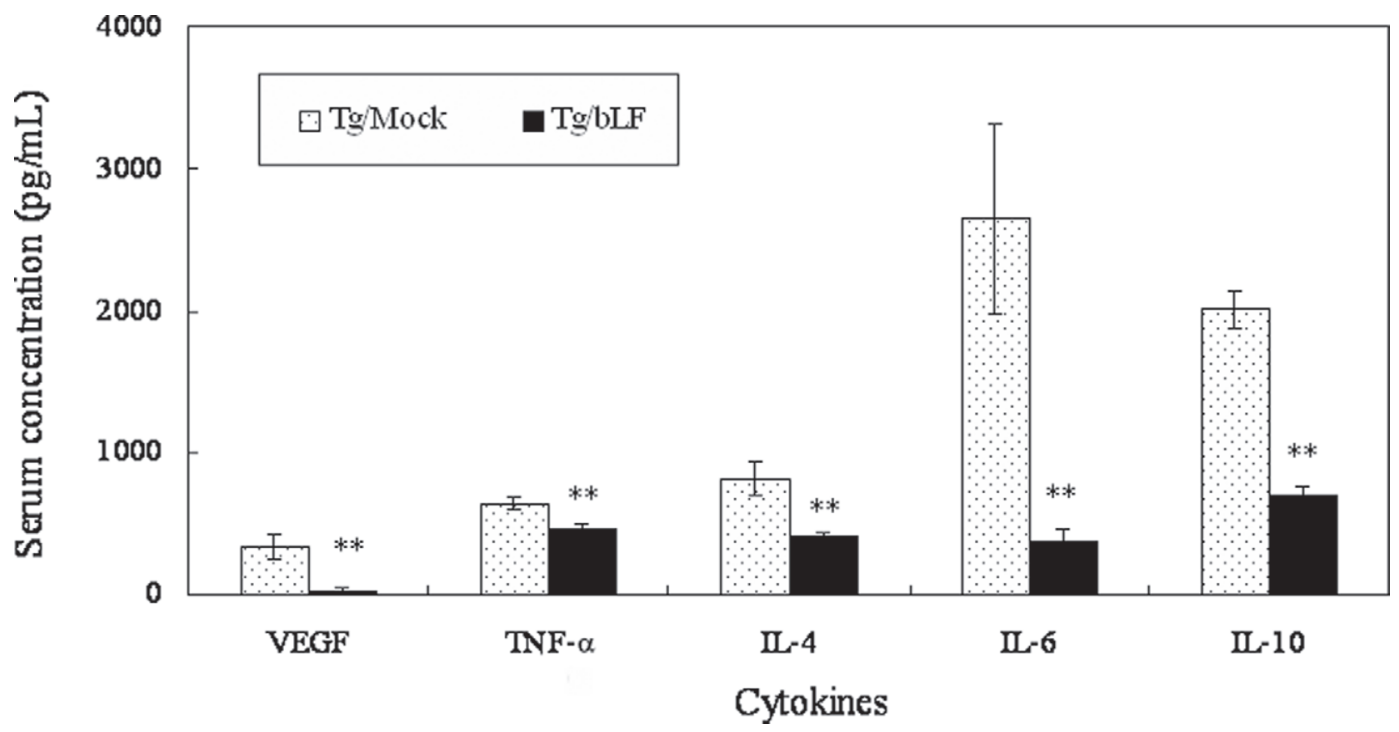

Figure 6. Cytokine levels of vascular endothelial growth factor (VEGF), tumor necrosis factor- $\alpha$ (TNF- $\alpha$ ), IL-4, IL-6, and IL-10 in the serum of 10.5-mo-old human vascular endothelial growth factor (VEGF) isoform $\mathrm{A}_{165}$ (hVEGF- $\mathrm{A}_{165}$ )-overexpressing transgenic mice determined by ELISA assays. The serum cytokine concentrations of hVEGF- $\mathrm{A}_{165}$-overexpressing transgenic mice treated with bovine lactoferrin (bLF) at 300 $\mathrm{mg} / \mathrm{kg}$ of BW 3 times a week for $1.5 \mathrm{mo}$ ( Tg/bLF group) were compared with the transgenic mice treated with PBS alone (Tg/Mock group). $* * P<0.01$ vs. Tg/Mock group.

development as an antiangiogenic agent in the treatment of lung cancer.

Bovine lactoferrin is a multifunctional protein without side effects. Yamauchi et al. (2000) found that administration of $2,000 \mathrm{mg} / \mathrm{kg}$ per day of bLF has no adverse effects in both sexes in rats and results in no apparent changes in food consumption, BW, ophthalmology, and urinalysis, including 1-d water intake, hematology (red blood cells, hemoglobin, hematocrit, mean corpuscular volume, mean corpuscular hemoglobin, mean corpuscular hemoglobin concentration, prothrombin time, activated partial thromboplastin time, and white blood cells), blood chemistry [glutamic oxaloacetic transaminase (GOT), glutamate pyruvate transaminase (GPT), lactate dehydrogenase (LDH), alkaline phosphatase (ALP), total cholesterol, total bilirubin, BUN, inorganic phosphorus, total protein, and albumin:globulin ratio], necropsy, organ weights, and histopathology. Furthermore, Shimamura et al. (2004) demonstrated that administration of $300 \mathrm{mg} / \mathrm{kg}$ per day of bLF suppresses tumor growth and metastasis in the mouse, which may be partly mediated by angiogenesis inhibition. In this study, we investigated the inhibition of pulmonary tumor formation through treatment with $300 \mathrm{mg} / \mathrm{kg}$ per day of bLF in a hVEGF-A $\mathrm{A}_{165^{-}}$ overexpressing transgenic mice model to present in situ lung tumors. We found that oral administration of bLF at $300 \mathrm{mg} / \mathrm{kg}$ of BW 3 times a week for $1.5 \mathrm{mo}$ to 10.5 -mo-old hVEGF- $\mathrm{A}_{165}$-overexpressing transgenic mice led to a dramatic decrease in solid tumor forma- tion compared with untreated transgenic mice (Table 1). Histological analysis showed that treatment with bLF reduced lung tumor formation and inflammation in hVEGF- $\mathrm{A}_{165}$-overexpressing transgenic mice (Figure 4). Moreover, immunohistochemical analysis showed that oral administration of bLF could reduce VEGF overexpression in Clara cells of the lung, which is related to vasculogenesis and angiogenesis. These processes are vital factors in the formation of tumors and in tumor growth, invasion, and metastasis. Bovine lactoferrin may act as an angiogenesis inhibitor, and thus have considerable potential in the treatment of lung cancer, because angiogenesis is necessary for the growth of a tumor beyond a few millimeters in diameter. Without angiogenesis, the tumor cannot access increased levels of oxygen and nutrients or remove waste. Previous studies also reported that bLF inhibited lung metastases, which was attributed to its antiangiogenic properties (Yoo et al., 1997). Shimamura et al. (2004) suggested that bLF participates as a regulator of angiogenesis, possibly by blocking endothelial function and inducing IL-18 production.

In this study, we demonstrated that VEGF-A, TNF- $\alpha$, IL-4, IL-6, and IL-10 could be decreased by bLF (Figure 6), which might inhibit cancer cell proliferation and stimulate cancer cell apoptosis (Bohlen et al., 2000; Alas et al., 2001; Sredni et al., 2004; Hong et al., 2007; Sethi et al., 2008). Additionally, treatment with bLF reduced the levels of these cytokines, resulting in restricted lung cancer growth. This may be a 
potential use for exploiting the activity of bLF against lung cancer for therapeutic purposes.

\section{CONCLUSIONS}

We found that bLF inhibited the expression of vegf mRNA and VEGF protein, which regulates angiogenesis. The suppression of angiogenesis by bLF is mediated by VEGF-A, and bLF inhibits tumor-induced angiogenesis in mice. These effects might comprise one of the mechanisms for the anticancer functions of bLF. This is the first paper using the in situ lung tumor model created by Clara cell-specific VEGF overexpression transgenic mice to understand the antitumor therapeutic effects of bLF through the suppression of inflammation and the VEGF pathway. Further study is underway to fully evaluate the mechanisms of bLF effects on tumorigenesis and to examine the potential use of bLF as a therapeutic agent.

\section{ACKNOWLEDGMENTS}

The authors thank Cheng-Wei Lai (Department of Life Sciences, National Chung Hsing University, Taichung, Taiwan) for the assistance in transgenic mice feeding and management. This research was supported in part by grants NSC-97-2313-B-005-004-MY3 and NSC-100-2313-B-005-028-MY3 from the National Science Council (Taipei, Taiwan, Republic of China) and the Ministry of Education (Taipei, Taiwan, Republic of China) under the ATU (Aiming for the Top University) plan. None of the authors has any financial or personal relationships that could inappropriately influence or bias the content of this paper.

\section{REFERENCES}

Alas, S., C. Emmanouilides, and B. Bonavida. 2001. Inhibition of interleukin 10 by rituximab results in down-regulation of bcl-2 and sensitization of B-cell non-Hodgkin's lymphoma to apoptosis. Clin. Cancer Res. 7:709-723.

Bohlen, H., M. Kessler, M. Sextro, V. Diehl, and H. Tesch. 2000. Poor clinical outcome of patients with Hodgkin's disease and elevated interleukin-10 serum levels. Clinical significance of interleukin-10 serum levels for Hodgkin's disease. Ann. Hematol. 79:110-113.

Chang, C. C., J. Y. Shih, Y. M. Jeng, J. L. Su, B. Z. Lin, S. T. Chen, Y. P. Chau, P. C. Yang, and M. L. Kuo. 2004. Connective tissue growth factor and its role in lung adenocarcinoma invasion and metastasis. J. Natl. Cancer Inst. 96:364-375.

Chen, C. M., H. L. Chen, T. H. C. Hsiau, A. H. Hsiau, H. Shi, G. J. Brock, S. H. Wei, C. W. Caldwell, P. S. Yan, and T. H. Huang. 2003. Methylation target array for rapid analysis of $\mathrm{CpG}$ island hypermethylation in multiple tissue genomes. Am. J. Pathol. 163:37-45.

Chen, H. L., J. Y. Huang, T. W. Chu, T. C. Tsai, C. M. Hung, C. C. Lin, F. C. Liu, L. C. Wang, Y. J. Chen, M. F. Lin, and C. M. Chen. 2008a. Expression of VP1 protein in the milk of transgenic mice: A potential oral vaccine against enterovirus 71 infection. Vaccine 26:2882-2889.
Chen, H. L., Y. W. Lai, C. S. Chen, T. W. Chu, W. Lin, C. C. Yen, M. F. Lin, M. Y. Tu, and C. M. Chen. 2010. Probiotic Lactobacillus casei expressing human lactoferrin elevates antibacterial activity in the gastrointestinal tract. Biometals 23:543-554.

Chen, H. L., L. C. Wang, C. H. Chang, C. C. Yen, W. T. Cheng, S. C. Wu, C. M. Hung, M. F. Kuo, and C. M. Chen. 2008b. Recombinant porcine lactoferrin expressed in the milk of transgenic mice protects neonatal mice from a lethal challenge with enterovirus type 71. Vaccine 26:891-898.

Chen, J. J., K. Peck, T. M. Hong, S. C. Yang, Y. P. Sher, J. Y. Shih, R. Wu, J. L. Cheng, S. R. Roffler, C. W. Wu, and P. C. Yang. 2001. Global analysis of gene expression in invasion by a lung cancer model. Cancer Res. 61:5223-5230.

Chen, Y. J., C. Y. Wu, C. C. Chang, C. J. Ma, M. C. Li, and C. M. Chen. 2008c. Nuclear Kruppel-like factor 4 expression is associated with human skin squamous cell carcinoma progression and metastasis. Cancer Biol. Ther. 7:777-782.

Chen, Y. J., C. Y. Wu, J. L. Shen, S. Y. Chu, C. K. Chen, Y. T. Chang, and C. M. Chen. 2008d. Psoriasis independently associated with hyperleptinemia contributing to metabolic syndrome. Arch. Dermatol. 144:1571-1575.

Coussens, L. M., and Z. Werb. 2002. Inflammation and cancer. Nature 420:860-867.

de Mejia, E. G., and V. P. Dia. 2010. The role of nutraceutical proteins and peptides in apoptosis, angiogenesis, and metastasis of cancer cells. Cancer Metastasis Rev. 29:511-528.

Duarte, D. C., A. Nicolau, J. A. Teixeira, and L. R. Rodrigues. 2011. The effect of bovine milk lactoferrin on human breast cancer cell lines. J. Dairy Sci. 94:66-76.

Ferlay, J., H. R. Shin, F. Bray, D. Forman, C. Mathers, and D. M. Parkin. 2010. Estimates of worldwide burden of cancer in 2008. Int. J. Cancer 127:2893-2917.

Ferrara, N. 2002. VEGF and the request for tumor angiogenesis factors. Nat. Rev. Cancer 2:795-803.

Ferrara, N., and T. Davis-Smyth. 1997. The biology of vascular endothelial growth factor. Endocr. Rev. 18:4-25.

González-Chávez, S. A., S. Arévalo-Gallegos, and Q. Rascón-Cruz. 2009. Lactoferrin: Structure, function and applications. Int. J. Antimicrob. Agents 33:301-306.

Hong, D. S., L. S. Angelo, and R. Kurzrock. 2007. Interleukin-6 and its receptor in cancer: implications for translational therapeutics. Cancer 110:1911-1928.

Hung, C. M., C. C. Yeh, H. L. Chen, C. W. Lai, M. F. Kuo, M. H. Yeh, W. Lin, M. Y. Tu, H. C. Cheng, and C. M. Chen. 2010. Porcine lactoferrin administration enhances peripheral lymphocyte proliferation and assists infectious bursal disease vaccination in native chickens. Vaccine 28:2895-2902.

Li, A. F., H. S. Hsu, C. Y. Hsu, A. C. Li, W. Y. Li, W. Y. Liang, and J. Y. Chen. 2010. A 20-year retrospective study of small-cell carcinomas in Taiwan. J. Surg. Oncol. 102:497-502.

Li, D., S. Sakashita, Y. Morishita, J. Kano, A. Shiba, T. Sato, and M. Noguchi. 2011. Binding of lactoferrin to IGBP1 triggers apoptosis in a lung adenocarcinoma cell line. Anticancer Res. 31:529-534.

Lin, S. S., K. C. Lai, S. C. Hsu, J. S. Yang, C. L. Kuo, J. P. Lin, Y. S. Ma, C. C. Wu, and J. G. Chung. 2009. Curcumin inhibits the migration and invasion of human A549 lung cancer cells through the inhibition of matrix metalloproteinase-2 and -9 and vascular endothelial growth factor (VEGF). Cancer Lett. 285:127-133.

Liu, F. C., H. L. Chen, K. Y. Chong, A. L. Hsu, and C. M. Chen. 2008. Production of recombinant porcine colipase secreted by Pichia pastoris and its application to improve dietary fat digestion and growth of postweaning piglets. Biotechnol. Prog. 24:1333-1341.

Lönnerdal, B., and S. Iyer. 1995. Lactoferrin: Molecular structure and biological function. Annu. Rev. Nutr. 15:93-110.

Masuda, C., H. Wanibuchi, K. Sekine, Y. Yano, S. Otani, T. Kishimoto, H. Tsuda, and S. Fukushima. 2000. Chemopreventive effects of bovine lactoferrin on N-butyl-N-(4-hydroxybutyl) nitrosamine-induced rat bladder carcinogenesis. Jpn. J. Cancer Res. 91:582-588.

Rodrigues, L., J. Teixeira, F. Schmitt, M. Paulsson, and H. L. Månsson. 2009. Lactoferrin and cancer disease prevention. Crit. Rev. Food Sci. Nutr. 49:203-217. 
Sethi, G., B. Sung, and B. B. Aggarwal. 2008. TNF: A master switch for inflammation to cancer. Front. Biosci. 13:5094-5107.

Shimamura, M., Y. Yamamoto, H. Ashino, T. Oikawa, T. Hazato, H. Tsuda, and M. Iigo. 2004. Bovine lactoferrin inhibits tumorinduced angiogenesis. Int. J. Cancer 111:111-116.

Singh, A. V., A. A. Franke, G. L. Blackburn, and J. R. Zhou. 2006. Soy phytochemicals prevent orthotopic growth and metastasis of bladder cancer in mice by alterations of cancer cell proliferation and apoptosis and tumor angiogenesis. Cancer Res. 66:1851-1858.

Sredni, B., M. Weil, G. Khomenok, I. Lebenthal, S. Teitz, Y. Mardor, Z. Ram, A. Orenstein, A. Kershenovich, S. Michowiz, Y. I. Cohen, Z. H. Rappaport, I. Freidkin, M. Albeck, D. L. Longo, and Y. Kalechman. 2004. Ammonium trichloro(dioxoethylene-o,o')tellurate (AS101) sensitizes tumors to chemotherapy by inhibiting the tumor interleukin 10 autocrine loop. Cancer Res. 64:1843-1852.

Tanaka, T., K. Kawabata, H. Kohno, S. Honjo, M. Murakami, T. Ota, and H. Tsuda. 2000. Chemopreventive effect of bovine lactoferrin on 4-nitroquinoline 1-oxide-induced tongue carcinogenesis in male F344 rats. Jpn. J. Cancer Res. 91:25-33.

Tsai, T. C., W. Lin, S. H. Yang, W. T. Cheng, E. H. Cheng, M. S. Lee, K. Y. Chong, and C. M. Chen. 2010. Granzyme G is expressed in the two-cell stage mouse embryo and is required for the maternalzygotic transition. BMC Dev. Biol. 10:88.

Tsuda, H., K. Sekine, J. Nakamura, Y. Ushida, T. Kuhara, N. Takasuka, D. J. Kim, M. Asamoto, H. Baba-Toriyama, M. A. Moore, H. Nishino, and T. Kakizoe. 1998. Inhibition of azoxymethane initiated colon tumor and aberrant crypt foci development by bovine lactoferrin administration in F344 rats. Adv. Exp. Med. Biol. 443:273-284

Tung, Y. T., H. L. Chen, C. W. Lai, C. J. Shen, Y. W. Lai, and C. M. Chen. 2011. Curcumin reduces pulmonary tumorigenesis in vascu- lar endothelial growth factor (VEGF)-overexpressing transgenic mice. Mol. Nutr. Food Res. 55:1036-1043.

Ushida, Y., K. Sekine, T. Kuhara, N. Takasuka, M. Iigo, M. Maeda, and H. Tsuda. 1999. Possible chemopreventive effects of bovine lactoferrin on esophagus and lung carcinogenesis in the rat. Jpn. J. Cancer Res. 90:262-267.

Xu, X. X., H. R. Jiang, H. B. Li, T. N. Zhang, Q. Zhou, and N. Liu. 2010. Apoptosis of stomach cancer cell SGC-7901 and regulation of Akt signaling way induced by bovine lactoferrin. J. Dairy Sci 93:2344-2350.

Yamada, Y., R. Sato, S. Kobayashi, C. Hankanga, O. Inanami, M. Kuwabara, Y. Momota, N. Tomizawa, and J. Yasuda. 2008. The antiproliferative effect of bovine lactoferrin on canine mammary gland tumor cells. J. Vet. Med. Sci. 70:443-448.

Yamauchi, K., T. Toida, S. Nishimura, E. Nagano, O. Kusuoka, S. Teraguchi, H. Hayasawa, S. Shimamura, and M. Tomita. 2000. 13-Week oral repeated administration toxicity study of bovine lactoferrin in rats. Food Chem. Toxicol. 38:503-512.

Yang, C. S., and X. Wang. 2010. Green tea and cancer prevention. Nutr. Cancer 62:931-937.

Yen, C. C., C. Y. Lin, K. Y. Chong, T. C. Tsai, C. J. Shen, M. F. Lin, C. Y. Su, H. L. Chen, and C. M. Chen. 2009. Lactoferrin as a natural regimen of selective decontamination of the digestive tract: Recombinant porcine lactoferrin expressed in the milk of transgenic mice protects neonates from pathogen challenges in the gastrointestinal tract. J. Infect. Dis. 199:590-598.

Yoo, Y. C., S. Watanabe, R. Watanabe, K. Hata, K. Shimazaki, and I. Azuma. 1997. Bovine lactoferrin and lactoferricin, a peptide derived from bovine lactoferrin, inhibit tumor metastasis in mice. Jpn. J. Cancer Res. 88:184-190. 